\title{
Pedicled Chimeric Perforator Flap Based on Inferior Gluteal Vessel Axis for the Reconstruction of Stage-Four Primary Ischial Pressure Sores-A New Design
}

\author{
Dharanipriya Arikrishnan ${ }^{1}$ Thalaivirithan Margabandu Balakrishnan ${ }^{1, \odot ~ J a g a n m o h a n ~ J a n a r d h a n a m ~}$
}

${ }^{1}$ Department of Plastic and Faciomaxillary Surgery, Madras Medical College, Chennai, India

Indian J Plast Surg:2021;54:177-185.
Address for correspondence Thalaivirithan Margabandu Balakrishnan, MBBS, MS, FRCS, DNB, DNB, MCh, Department of Plastic and Faciomaxillary Surgery, Madras Medical College, Old No. 15/New No. 10, Thiruvalluvar Street, Kodambakkam,Chennai 600024, India (e-mail: thalaiviri.b@gmail.com).

\begin{abstract}
Keywords

- recurrent pressure ulcer

- ischial pressure ulcer

- myelopathic patients

- chimeric inferior gluteal artery perforator flap

Background "Subfascial void reconstruction" in ischial pressure sores (IPSs) goes a long way in the amelioration of the common complications like persistent drainage, infection, wound dehiscence, and late recurrence. No locoregional flaps suffice this requirement. So we have designed a chimeric pedicled flap based on the inferior gluteal vessel axis (IGVA) perforators with two tissue components: (1) Pacman-style fasciocutaneous flap on a perforator and (2) gluteus maximus muscle (inferior portion) on another independent perforator.

Aim and Methods After confirming the feasibility of novel design of chimeric pedicled IGVA perforator flap with cadaver study, we embarked on the clinical study with this chimeric flap. In this prospective cohort study, the study and the control existed in the same patient so that the biological factors affecting the wound healing would be the same.

Results Twenty-one patients were included whose mean age was 39 years. Late recurrence occurred in one patient (4.8\%) of chimeric flap while the control group (who had undergone conventional reconstruction) had recurrence in 11 patients (52.4\%). On assessment with overall institutional score, grade A was observed in 18 patients of the chimeric IGVA flap group $(p<0.045)$, and in only 3 patients of the control group. Conclusions This anatomically construed flap, a new addendum in the armamentarium of reconstruction of IPSs, with its potential to congruently fill the ischiogluteal subfascial void may provide a lasting solution for preventing recurrences.
\end{abstract}

\section{Introduction}

Ischial pressure sores (IPSs) are the most commonly encountered pressure ulcers and also have a high tendency for recurrences. These IPSs are typically inverted flask-shaped ulcers with a large and deep pseudobursal extension over the irregularly prominent ischial tuberosities. These are attributed to the following reasons: (1) the paretic gluteus maximus uncovers the ischial tuberosity, which drives the heavyweight of the whole trunk (during the sitting posture) through the

(C) 2021. Association of Plastic Surgeons of India.

This is an open access article published by Thieme under the terms of the Creative Commons Attribution-NonDerivative-NonCommercial-License, permitting copying and reproduction so long as the original work is given appropriate credit. Contents may not be used for commercial purposes, or adapted, remixed, transformed or built upon. (https://creativecommons.org/licenses/by-nc-nd/4.0/). Thieme Medical and Scientific Publishers Pvt. Ltd. A-12, 2nd Floor, Sector 2, Noida-201301 UP, India 
gluteal pad of fat; (2) proximity to the incontinent anus and narrow opening of the ulcer promote chronic biofilm in the IPSs; and (3) the chronic shear forces in the sitting posture cause the pseudobursal sinus suppurative extension into the atrophied ishcioanal fossa. ${ }^{1-5}$ There are four tenets in the surgical principle for the treatment of stage-four IPSs: (1) optimizing the general condition of the patient before surgery, ${ }^{6}$ (2) converting the chronic contaminated wound into an acute clean wound by a complete "pseudotumor" excision ${ }^{6-8}$ of the ulcer (this step results invariably in the large and deep composite subfascial void), (3) tension-free reconstruction with well-vascularized tissues, obliterating the subfascial void forms a good bulk over the decorticated ischial bony stump (at the same time, the prospect of other locoregional flaps should not be violated), ${ }^{9}$ and (4) postoperative education about local hygiene and offloading the ischial region should be emphasized to all patients. The currently available conventional flaps do not have all the ingredients to suffice the above said third surgical principle. ${ }^{10-19}$ This disregarded step in the reconstruction is the potential cause for the persistent discharge, infection, wound dehiscence, sinus, and late recurrence. ${ }^{9,20,21}$ Also, these commonly used flaps are subverted by the absence of an independently mobile muscle component on a perforator. Therefore the "subfascial void reconstruction" in the stage-four IPSs (according to National Pressure Ulcer Advisory Panel [NPUAP]) goes a long way in the amelioration of these common complications. So, we designed a chimeric pedicled flap based on the inferior gluteal vessel axis (IGVA) perforators with two tissue components: (1) a Pacman-style fasciocutaneous flap component ${ }^{22}$ and (2) the inferior portion of the gluteus maximus muscle, harvested on another independent perforator from the same source. The Pacman-style fasciocutaneous flap component has the advantage of reusability and homogenous high vascularity to reconstruct the suprafascial defect of IPSs. ${ }^{22}$ The lower third gluteus maximus muscle harvested on an independent perforator, bestowed with freedom of mobility, facilitates the three-dimensional spatial positioning. This also provides a well-vascularized tissue to fill and obliterate congruently the large and deep subfascial void of the excised IPSs effectively to eschew the aforesaid complications. A preliminary cadaver study was conducted by us to confirm the feasibility of harvesting a true intrinsic chimeric pedicled perforator flap based on the IGVA. Later, we embarked on a clinical study with this new design of the flap for the reconstruction of primary stage-four IPSs.

\section{Aim of the Cadaver Study}

A cadaver dissection study was conducted to study the anatomy of the extra pelvic portion of the IGVA and to assess the feasibility of harvesting the true intrinsic pedicled chimeric IGVA perforator flap with two tissue components: (1) a muscle component based on a musculocutaneous/muscle perforator and (2) a separate fasciocutaneous paddle based on either a musculocutaneous or septofasciocutaneous perforator.

\section{Aim of the Clinical Study}

A clinical application of this cadaver study was then performed in the primary bilateral stage-four IPSs. A prospective cohort clinical study was conducted to evaluate the clinical outcomes of the pedicled chimeric IGVA perforator flaps for the reconstruction of the stage-four primary IPSs compared with the simultaneously performed conventional gluteus maximus musculocutaneous flap/muscle with fasciocutaneous flap reconstructions on the contralateral side in the same patients.

\section{Materials and Methods}

Institutional ethical committee approval was obtained for conducting both cadaver and clinical studies. All the participants provided written informed consent for using their photographs and clinical materials for research and publication purposes.

\section{Cadaver Study-Methods and Results}

A preliminary cadaver dissection study was conducted in 2015. The cadavers with damaged gluteal area were excluded. Twenty specimens in 10 fresh adult cadavers (5 males and 5 females) were dissected. Before the dissection, retrograde injection of red lead oxide and methylene blue was given into the common iliac artery and vein, respectively. The cadavers were frozen overnight. Then the specimens were dissected. The gluteal triangle was marked with these points: (a) the posterior superior iliac spine, (b) the subcutaneous palpable ischial tuberosity, and (c) the superior part of the greater trochanter of the femur (-Fig. 1). The incision was made along the inferior gluteal fold and the maximum numbers of perforators were located in the subcutaneous plane above the epimysium of the inferior part of gluteus maximus. By a combination of retrograde and anterograde techniques, the perforators were dissected toward the medial and lateral branches and the main trunk of IGVA ( - Figs. $\mathbf{2}$ and $\mathbf{3}$ ). The perforators and branches were measured with calipers and scales, and the measurements were always taken at their origins.

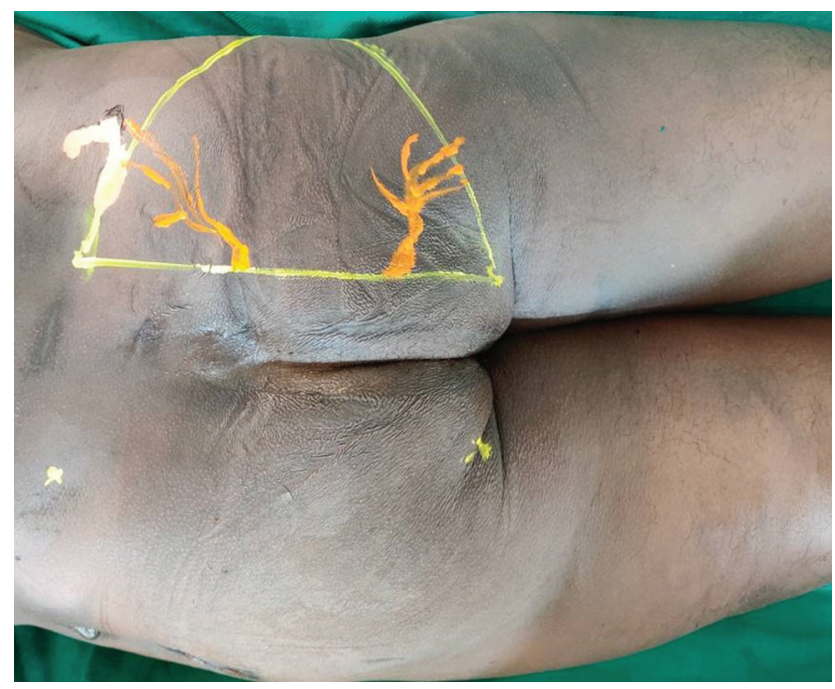

Fig. 1 Gluteal triangle marked in the cadaver. 


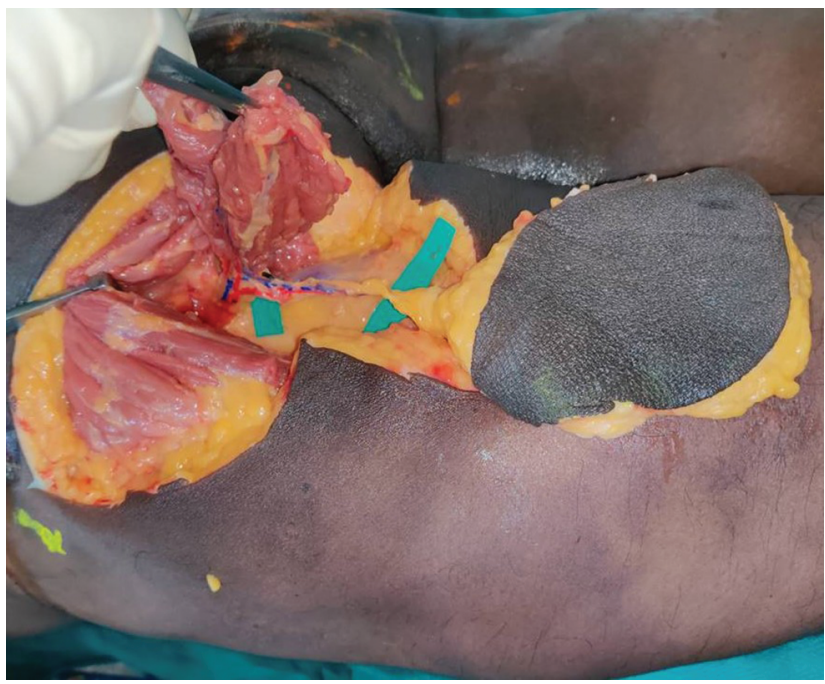

Fig. 2 Chimeric pedicled perforator flap based on inferior gluteal vessel axis (IGVA) harvested in the cadaver.

The average dimensions of the extrapelvic trunk of IGVA were $1.25 \mathrm{~cm}$ in length and $2.75 \mathrm{~mm}$ in diameter. The extrapelvic portion of IGVA always possessed two equal-sized venae comitantes. Other anatomical data of IGVA are tabulated (-Table 1). The anatomical study established that the design of chimeric flap based on the IGVA was possible. The septofasciocutaneous perforators were mainly arising from the medial branch, which runs obliquely downward toward the inferior medial border of the gluteus maximus muscle very close to the ischial tuberosity, where it enters the subcutaneous plane. It was descending between the anterior aspect of gluteus maximus and the posterior aspect of the following muscles-gemelli with obturator internus and quadratus femoris (in craniocaudal sequence). The maximum number of musculocutaneous perforators was traced toward the medial branch of the IGVA. Most of the perforators were seen in the inferior medial border of the gluteus maximus

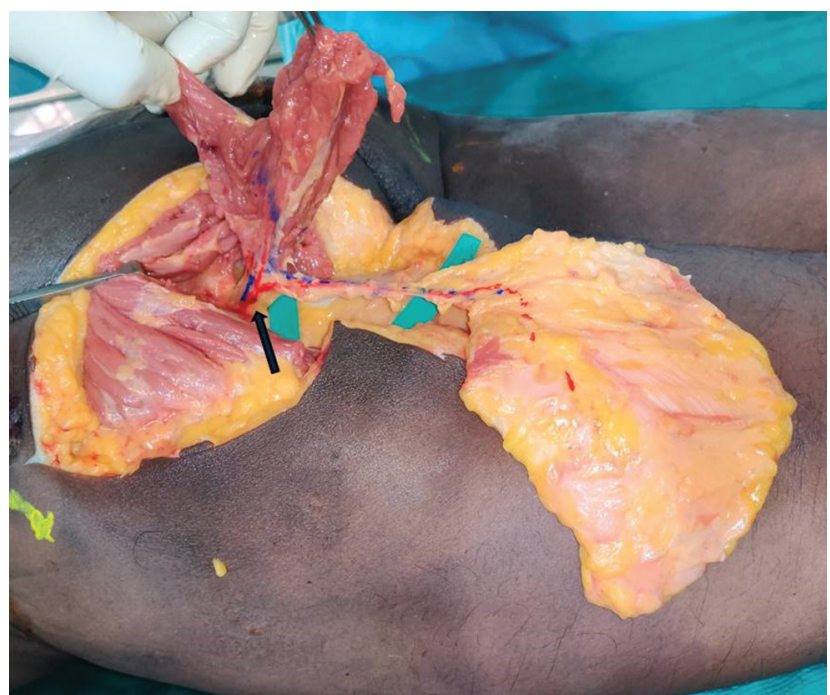

Fig. 3 The components of the chimeric flap showing cutaneous paddle on long septofasciocutaneous perforator and islanded muscle paddle on another independent musculocutaneous perforator (arrow showing the stem of inferior gluteal vessel axis [IGVA]).

in the medial third of the line drawn from the tip of the greater trochanter to ischial tuberosity. The dissection study revealed that muscle could be divided at its origin from the sacrotuberous ligament as well as distally and laterally from its aponeurotic attachment to the iliotibial tract to get the desired amount of muscle island on a single best perforator from the medial branch of the IGVA. The average length of the perforator after periperforator dissection up to the trunk was $3.5 \mathrm{~cm}$. It was also established that it was possible to harvest the fasciocutaneous skin paddle on an average length of $3.75 \mathrm{~cm}$ musculocutaneous or septofasciocutaneous perforator (rendered directly by the periperforator dissection). The lateralmost perforator from the medial branch of IGVA when chosen for the muscle island will provide a wider arc of rotation.

Table 1 Cadaver study-anatomical data of the extrapelvic part of pedicled inferior gluteal vessel axis (IGVA)

\begin{tabular}{|l|l|l|l|l|}
\hline $\begin{array}{l}\text { Segments } \\
\text { of the } \\
\text { extrapelvic } \\
\text { part of IGVA }\end{array}$ & $\begin{array}{l}\text { Number of branches/ } \\
\text { perforators (mode; } \\
\text { range) }\end{array}$ & $\begin{array}{l}\text { Type of branches/ } \\
\text { perforators }\end{array}$ & $\begin{array}{l}\text { Diameter }(\mathrm{mm}) \text { of the } \\
\text { branches/perforators } \\
\text { (mean; range) }\end{array}$ & $\begin{array}{l}\text { Composition of branches/ } \\
\text { perforators }\end{array}$ \\
\hline Trunk of IGVA & $\begin{array}{l}2 \text { number of branches; } \\
\text { min 2, max 4 }\end{array}$ & Muscular branches & $1.5 ;$ min 1.2, max 2.75 & All with one accompanying vein. \\
\hline $\begin{array}{l}\text { Medial } \\
\text { branch }\end{array}$ & $\begin{array}{l}5 \text { number of perforators; } \\
\text { min 3, max 8 }\end{array}$ & $\begin{array}{l}\text { Average 5.2 MCP and 2.4 } \\
\text { SFCP (between gluteus } \\
\text { maximus posteriorly and } \\
\text { gemelli, obturator inter- } \\
\text { nus and quadratus femoris } \\
\text { anteriorly). }\end{array}$ & $\begin{array}{l}2 ; \\
\text { min1.5m, max 2.5 }\end{array}$ & $\begin{array}{l}\text { All MCP and SFCP perforator } \\
\text { were accompanied by two vena } \\
\text { comitantes. } \\
\text { On an average 1.5 number of } \\
\text { SFCP were accompanied by the } \\
\text { clunial cutaneous nerves. } \\
\text { And all these had single accom- } \\
\text { panying vein. }\end{array}$ \\
\hline $\begin{array}{l}\text { Lateral } \\
\text { branch }\end{array}$ & $\begin{array}{l}1 \text { number of perforators } \\
\text { Min- 1, Max-4 }\end{array}$ & $\begin{array}{l}\text { All of them were MCP. } \\
\text { On an average 1.5 number } \\
\text { of neurocutaneous per- } \\
\text { forators (to the posterior } \\
\text { cutaneous nerve of thigh } \\
\text { and the sciatic nerve) }\end{array}$ & $\begin{array}{l}1.75 \text { mm (perforators) } \\
\text { (neurocutaneous } \\
\text { branches) }\end{array}$ & $\begin{array}{l}\text { All had single accompanying } \\
\text { vein. Always gave one neuro- } \\
\text { cutaneous perforator to the } \\
\text { posterior cutaneous nerve of } \\
\text { thigh and sciatic nerve. }\end{array}$ \\
\hline
\end{tabular}

Abbreviations: Max, maximum; MCP, musculocutaneous perforator; min, minimum; SFCP, septofasciocutaneous perforator. 


\section{Clinical Study}

In this study, we had selected only bilateral stage-four primary IPSs which required ostectomy rendering a large composite void. We had performed the chimeric pedicled IGVA flap reconstruction on one side (randomly chosen). On the other side, we used conventional musculocutaneous flap (biceps femoris myocutaneous $\mathrm{V}-\mathrm{Y}$ advancement flap, $n=8$ ) or muscle flap with local fasciocutaneous flaps (gluteal rotation fasciocutaneous flap with turn over gluteus maximus flap, $n=10$; biceps femoris advancement flap with local rotation flap, $n=3$ ) on the other side in the same patient. The study comprised 21 patients ( 7 females and 14 males) who were operated and followed-up between 2015 and 2019.

\section{Inclusion Criteria}

The inclusion criteria are as follows:

- All primary cases of bilateral ischial pressure sore NPUAP stage four.

- Those with a good general condition to undergo both excision and reconstruction in single stage.

- Those with good acoustic signals on Doppler study of the IGVA perforators.

\section{Exclusion Criteria}

The exclusion criteria are as follows:

- Those with co-morbidities like diabetes, hypertension, cardiac disease, or respiratory compromise.

- Those with severe malnutrition and wasting.

- Chronic smokers who have not stopped smoking.

- Those with spasms of the lower limbs.

- Those with fracture pelvis with a compromise of the internal iliac vessels.

- Those lost to follow-up.

\section{Surgical Technique}

Patients were investigated for involvement of ischial tuberosity by X-ray of the pelvis-AP/ lateral ( - Fig. 4). This also reveals any fractures, subluxations, dystrophic calcifications of pseudobursa, and cystolithiasis, if present. All cases were prepared on an average of 1.5 debridement before definitive surgical intervention. They were treated with wound and bone biopsy culture-directed antibiotic therapy. Standard preoperative preparations were followed. The side of the chimeric IGVA flap was randomly chosen and with the patient in the lateral posture with fully flexed hip, the perforators were located by $10 \mathrm{MHz}$ Doppler along the line joining the ischial tuberosity and the upper aspect of greater trochanter.

All the surgeries were performed under general anesthesia with the patient in the jackknife position (with soft padding of all bony prominences). After pseudotumor excision, gentamicin saline wash was given. A Pacman-styled fasciocutaneous flap was marked incorporating the previously marked perforator and centered over the line joining the ischial

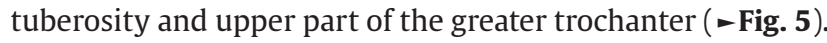
The biogeometry elicited by Balakrishnan et $\mathrm{al}^{22}$ was followed. A nondelineating incision was placed ( - Fig. 6). The flap was raised in a supra epimysial plane to locate septofasciocutaneous and musculocutaneous perforators (-Figs. 6 and 7). A large pulsatile perforator with venae comitantes was chosen for the Pacman fasciocutaneous island and traced toward the medial branch of the IGVA. The incision was completed for the Pacman-style flap and it was islanded

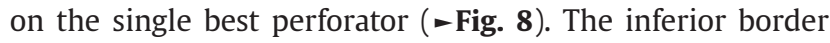
of the gluteus maximus was retracted and a large perforator to the lower fiber of the gluteus maximus, which was pulsatile with venae comitantes, was chosen and traced toward the medial branch of IGVA. The lower one-third fibers of the gluteus maximus starting from the aponeurosis toward the sacrotuberous ligament, with adequate dimension to fill the subfascial void, were harvested on this single best perforator (-Fig. 9). An attempt was always made as per the cadaver study finding to choose the lateralmost perforator to get a wider arc. IGVA was dissected toward its exit from greater sciatic foramen to facilitate mobility ( - Fig. 10). The muscle island was positioned over the shaved-off ischial tuberosity and congruently filled into the ishcioanal region and fixed to

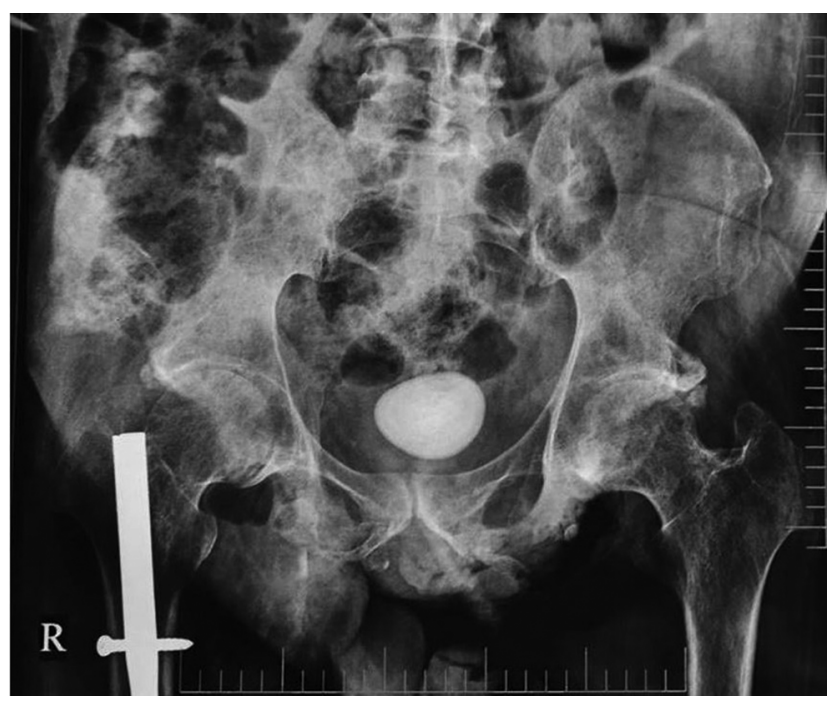

Fig. 4 Preoperative X-ray showing osteomyelitic destruction of ischial tuberosity on either side with cystolithiasis and intramedullary nailing of right femur proximal third fracture.

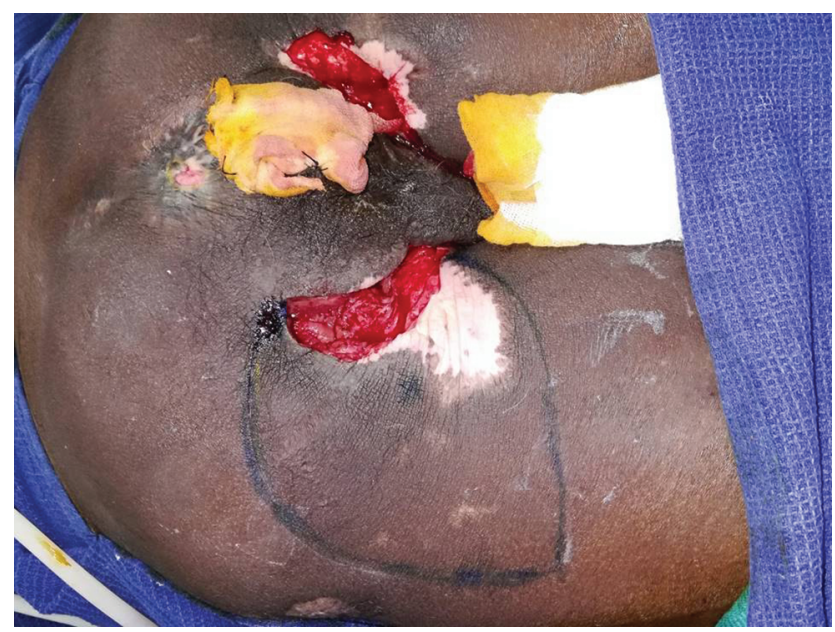

Fig. 5 Intraoperative picture showing the Pacman flap marked in the territory of Dopplered perforator. 


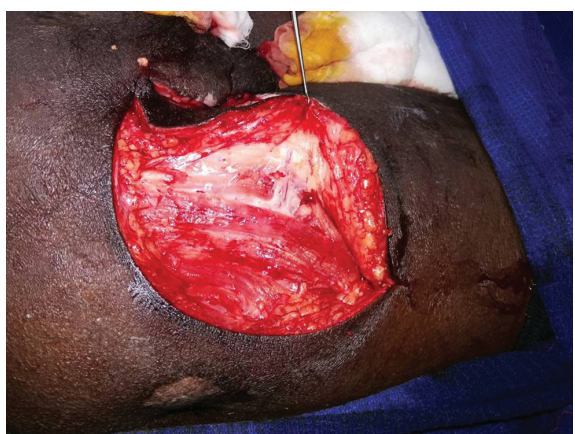

Fig. 6 The superior nondelineating incision with supraepimysial dissection showing the musculocutaneous perforator through the lower third oblique portion of the gluteus maximus.

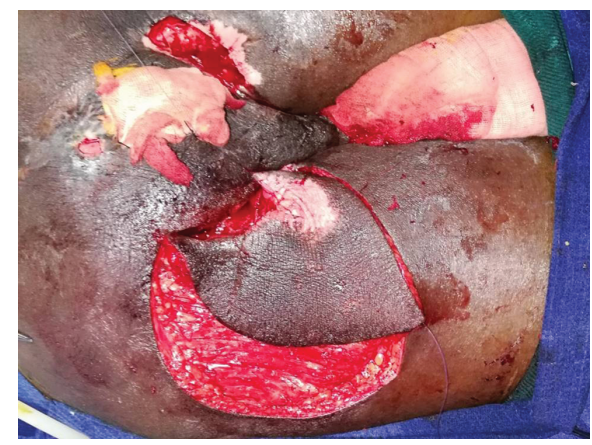

Fig. 8 Intraoperative picture showing islanded Pacman perforator flap.

the deeper recess of the cavity (Video 1). The Pacman flap was mobilized by incorporating both V-Y advancement and transposition (jaws of the Pacman) movement ( - Fig. 11). A suction drain was placed through a separate stab incision. On the other side after pseudotumor excision, a conventional biceps femoris/gluteus maximus muscle flap with fasciocutaneous flap or biceps femoris musculocutaneous flap was done.

\section{Video 1}

Intraoperative video showing fixation of islanded muscle on an independent perforator in the deeper recess of the ishcioanal region. Online content including video sequences viewable at: https://www.thieme-connect. com/products/ejournals/html/10.1055/s-0041-1729505.

Standard postoperative protocol was followed. Drains were removed when the output was less than $30 \mathrm{~mL}$ per day. Postoperative antibiotics were continued for a week's time. Personal and perineal hygiene was taught to the patients. Patients were discharged between 10 and 14 days after surgery with instructions to offload the operated area. Self-ambulation in the wheelchair with proper offloading of the operated area was initiated after 4 weeks. Patients were followed-up every month for the initial 6 months and then followed-up once in 2 months later. In this prospective cohort study, the study and the control existed in the same patient, so that the biological factors affecting wound healing would be the same.

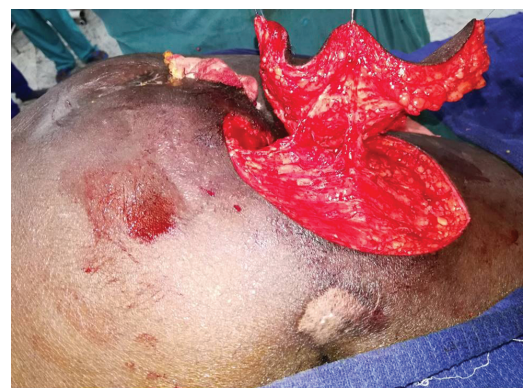

Fig. 7 Intraoperative picture showing Pacman-style fasciocutaneous flap elevated on two perforators before the selection of single best perforator.

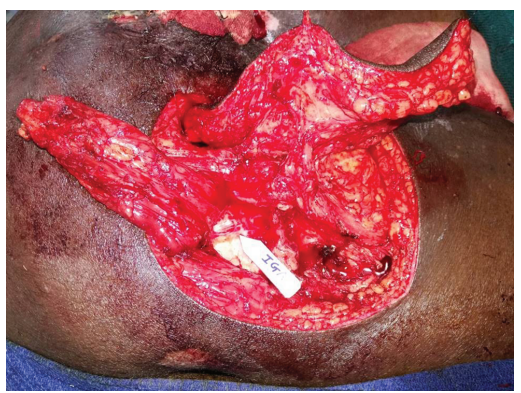

Fig. 9 Intraoperative picture showing chimeric configuration of pedicled inferior gluteal vessel axis (IGVA) perforator flaps with muscle island and fasciocutaneous island on separate perforator of IGVA.

\section{Case Illustration 1}

A 55-year-old paraparetic man with history of burst fracture dislocation D12 vertebra presented with bilateral stage-four ischial pressure sore ( - Fig. 12). On both sides, there were large pseudobursa extending on to ishcioanal fossa and intermuscular recess. After pseudotumor excision on the left side, with the shaving off the irregular outer cortex of ischial tuberosity, $14 \mathrm{~cm} \times 12 \mathrm{~cm}$ Pacman flap, and $10 \mathrm{~cm} \times 4 \mathrm{~cm} \times 2 \mathrm{~cm}$ gluteus maximus muscle on two independent perforators from IGVA were harvested in a chimeric fashion. The muscle was positioned in a tensionless manner over the decorticated ischial tuberosity into the ishcioanal fossa and fixed to the periosteum in the deeper recess (Video 1). Then the Pacman flap was moved over this muscle flap to cover the cutaneous defect.

On the other side after pseudotumor excision, the gluteus maximus turnover flap was done. We found, as in all cases, that only the aponeurotic portion of the inferior third of gluteus maximus was hardly reaching the decorticated ischial tuberosity and fixed in that position. Over this fasciocutaneous rotation flap was done for the surface defect.

A suction drain was placed on either side. From the right side, the drain was removed on the tenth day and from the left side on the second day. The patient was discharged on the 14th day. Wounds healed uneventfully ( - Fig. 12) and the patient was followed-up for 24 months with no recurrence. He was ambulant with crutches and wheelchair.

\section{Case Illustration 2}

A 33-year-old woman developed bilateral ischial pressure sores following Guillian-Barre syndrome. She had large 


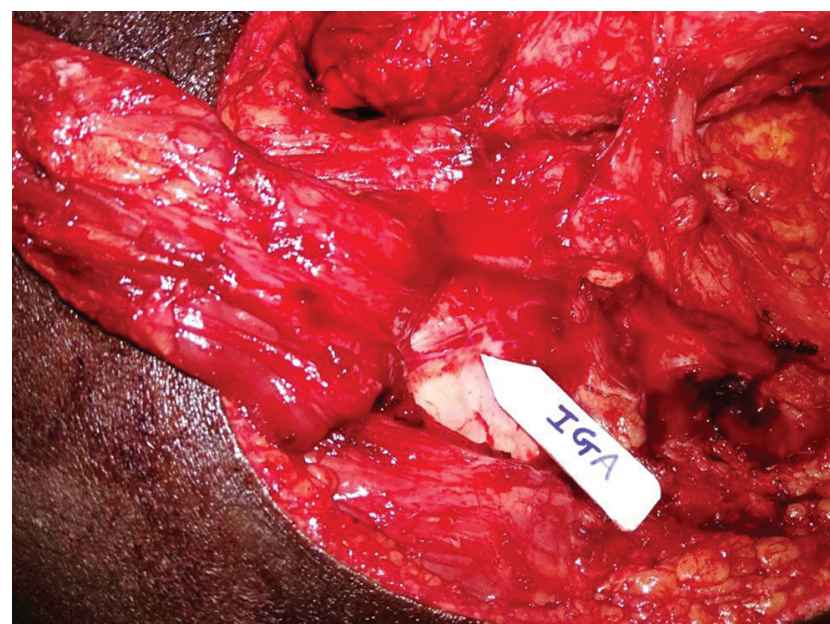

Fig. 10 Intraoperative picture showing IGVA dissected unto the greater sciatic foramen.

stage-four ischial pressure sores with overhanging wound edges with classical "flask-shaped ulcers" ( - Fig. 13). Her pelvic X-ray revealed bilateral ischial tuberosity superficial sequestrations (-Fig. 13). Her nutritional, neurological, anemia, and general conditions were treated and stabilized before surgery. The steroids were discontinued and concurrently treated with vitamin A supplements to promote wound healing. After pseudotumor excision with limited ischial ostectomies (-Fig. 13), the large rotation flap with biceps femoris advancement was done on the left side and pedicled chimeric IGAP flap was done on

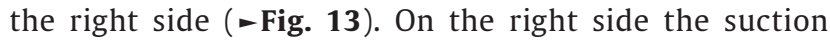
drain was removed on the fourth postoperative day. On the left side, though drain was removed on the sixth day there was continued ooze through the dehisced wound for 7 days and then it healed secondarily. There was uneventful healing on the chimeric IGAP flap side. There was recurrence on the rotation flap site at 6 months and that was treated by excision and further rotation and advancement. After that she was followed-up for 26 months and she remained ulcer free despite ambulation on the wheelchair (-Fig. 13).

\section{Results}

\section{Results of the Clinical Study}

Twenty-one cases patients included whose mean age was 39 years. The demographic details of patients are tabulated (-Table 2). All the patients were operated as described earlier in the surgical procedure. The mean surface area of the cutaneous paddle and muscle paddle in the pedicled chimeric IGVA flap group was $150.74 \mathrm{~cm}^{2}$ and $44.40 \mathrm{~cm}^{2}$, respectively. The mean thickness of the muscle paddle in the pedicled chimeric IGVA flap was $1.75 \mathrm{~cm}$ (range $1.25-2 \mathrm{~cm}$ ). We observed that the islanded, adequately sized muscle paddle on an independent perforator not only congruently filled the subfascial ischiogluteal void, but it also reached all the recesses in a tensionless manner. The mean flap surface area in the contralateral control group was $147.19 \mathrm{~cm}^{2}$. All the

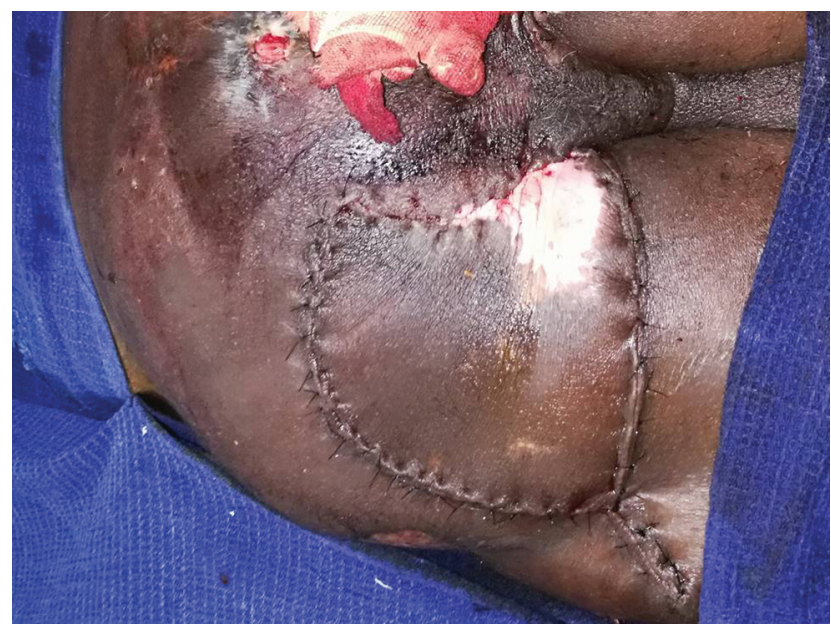

Fig. 11 Intraoperative picture showing inset of Pacman flap incorporating transposition and rotation of jaws of the Pacman and V-Y advancement of entire fasciocutaneous perforator flap.

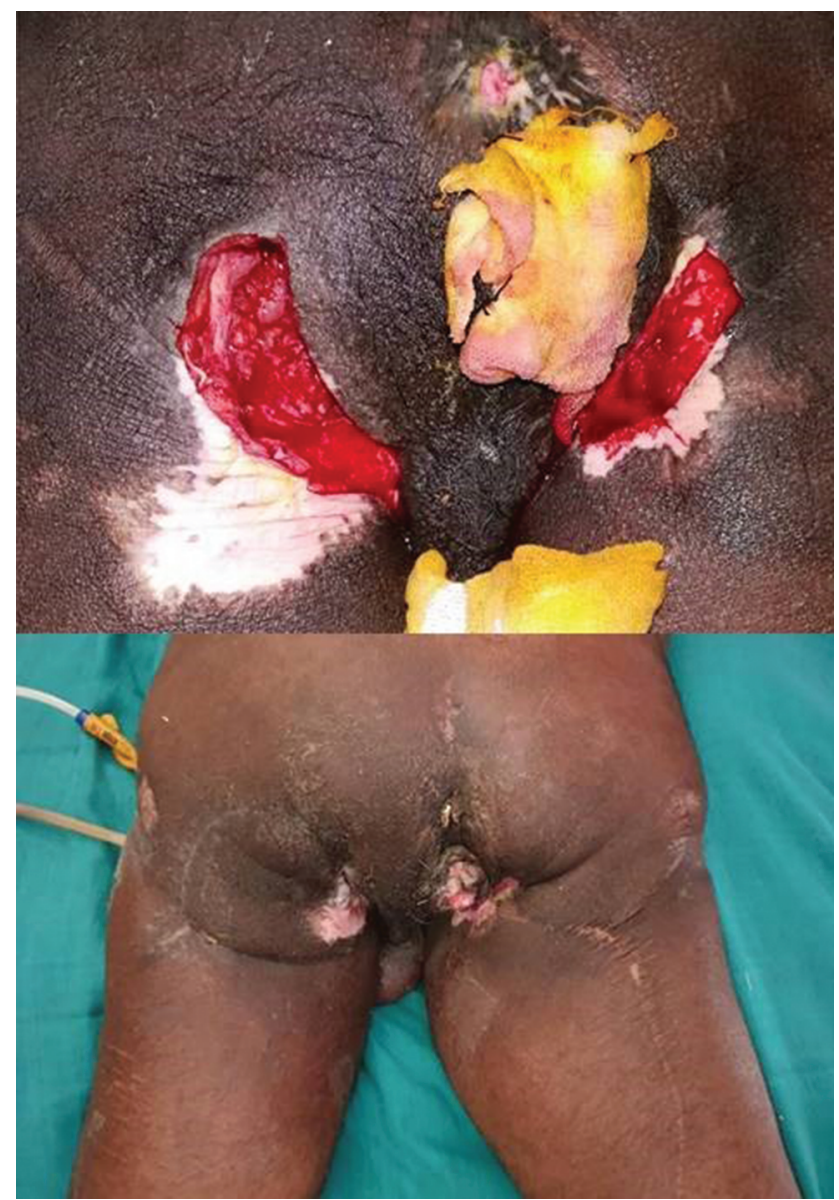

Fig. 12 Case 1 illustrations. Above: intraoperative picture after debridement of ischial pressure sores (IPSs) on either side. Below: postoperative picture at 24 months follow-up.

patients were under close observation in the postoperative period. The mean days taken for drain removal were 3.5 days in the chimeric flap group and 9.5 days in the control group. There existed a six-day difference between the chimeric IGVA flap reconstructed site and conventionally reconstructed 


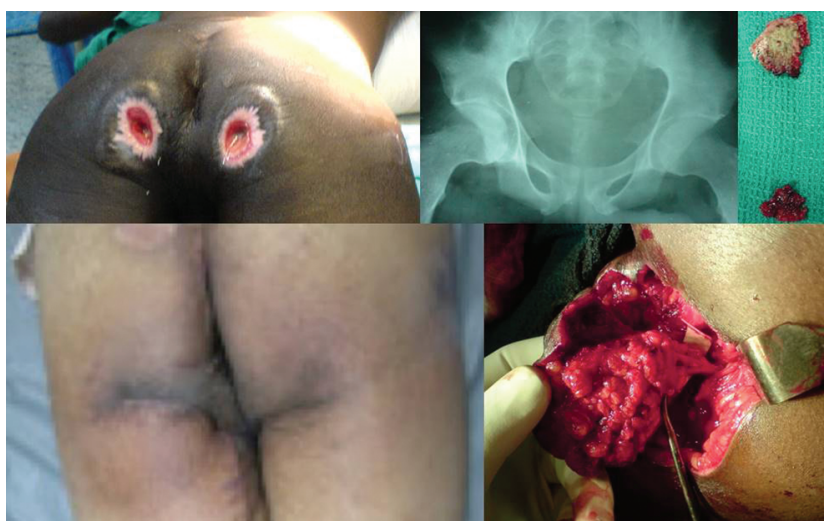

Fig. 13 Case 2 illustrations. Upper left: preoperative picture. Upper middle: preoperative AP view of the X-ray pelvis showing bilateral ischial tuberosity sequestrations. Upper right: intraoperative picture showing limited ostectomy specimens. Lower right: intraoperative picture showing a skin paddle raised on a single best perforator from the pedicled inferior gluteal vessel axis (IGVA). Lower left: postoperative picture at 26 months follow-up. site $(p=0.035)$. The infection rate was lesser in the chimeric IGVA flap group (4.76\%) when compared with the control group $(28.57 \%)(p=0.038)$. On comparing wound dehiscence in both the groups, the chimeric IGVA flap group had the complication in only 2 patients $(9.52 \%)$, whereas the control group had dehiscence in 10 patients $(47.62 \%)(p=0.006)$. The early wound dehiscence due to venous congestion and subsequent suture removal had occurred in 7 patients of control group but none was noted in the chimeric IGVA group. There was no partial or complete flap loss on both reconstruction sites. All the patients were followed-up for an average period of 26 months. Recurrence was noted in only one patient $(4.76 \%)$ in the pedicled chimeric IGVA flap group while the control group had an alarmingly high recurrence rate of $52.38 \%$ ( 11 out of $21 ; p=0.0006$ ). The overall institutional score ( - Table $\mathbf{3}$ ) was calculated for assessing the outcomes. It was found that in the chimeric IGVA flap group, 18 patients $(85.71 \%)$ had grade A (excellent; $p<0.045$ ), two patients (9.52\%) had grade B (good), and one patient (4.76\%)

Table 2 Demographic details of the patients

\begin{tabular}{|c|c|c|c|c|c|c|c|c|}
\hline \multirow[t]{2}{*}{\begin{tabular}{|l} 
S. \\
No.
\end{tabular}} & \multirow[t]{2}{*}{\begin{tabular}{|l|} 
Age \\
(Years)
\end{tabular}} & \multirow[t]{2}{*}{ Gender } & \multirow[t]{2}{*}{$\begin{array}{l}\text { Cause of } \\
\text { myelopathy }\end{array}$} & \multicolumn{2}{|c|}{ Chimeric IGVA perforator flap } & \multirow[t]{2}{*}{$\begin{array}{l}\text { Control group } \\
\text { cutaneous paddle size } \\
(\mathrm{cm}) \text { and surface area } \\
\left(\mathrm{cm}^{2}\right)\end{array}$} & \multicolumn{2}{|c|}{$\begin{array}{c}\text { Overall } \\
\text { institutional score } \\
\text { at the end of } \\
\text { follow-up }\end{array}$} \\
\hline & & & & $\begin{array}{l}\text { Cutaneous paddle size } \\
(\mathrm{cm}) \text { and surface area } \\
\left(\mathrm{cm}^{2}\right)\end{array}$ & $\begin{array}{l}\text { Muscle paddle } \\
\text { size }(\mathrm{cm}) \text { and surface } \\
\text { area }\left(\mathrm{cm}^{2}\right)\end{array}$ & & $\begin{array}{l}\text { Chimeric } \\
\text { IGVA } \\
\text { Flap }\end{array}$ & Control \\
\hline 1 & 44 & M & Trauma & $14 \times 11(154)$ & $12 \times 4.5(54)$ & $14 \times 10.5(147)$ & B & C \\
\hline 2 & 36 & M & Trauma & $12.5 \times 10(125)$ & $10 \times 3(30)$ & $12 \times 10.5(126)$ & A & A \\
\hline 3 & 28 & $\mathrm{~F}$ & $\begin{array}{l}\text { Transverse } \\
\text { myelitis }\end{array}$ & $15 \times 12.5(187.5)$ & $11.5 \times 5(57.5)$ & $15 \times 12(180)$ & A & D \\
\hline 4 & 55 & M & Trauma & $14 \times 12(168)$ & $10 \times 4(40)$ & $14 \times 11.5(161)$ & A & B \\
\hline 5 & 34 & $\mathrm{~F}$ & Trauma & $13 \times 10.5(136.5)$ & $10 \times 3(30)$ & $13 \times 10(130)$ & A & C \\
\hline 6 & 45 & M & Trauma & $13.5 \times 11(148.5)$ & $10.5 \times 4(42)$ & $13 \times 11.5(149.5)$ & A & D \\
\hline 7 & 33 & $\mathrm{~F}$ & GBS & $14 \times 11(154)$ & $11 \times 4.5(49.5)$ & $13.5 \times 11(148.5)$ & A & C \\
\hline 8 & 32 & M & Trauma & $15 \times 12.5(187.5)$ & $12 \times 5(60)$ & $14 \times 12(168)$ & A & D \\
\hline 9 & 27 & M & Trauma & $12.5 \times 10(125)$ & $10 \times 3(30)$ & $12 \times 10.5(126)$ & A & C \\
\hline 10 & 63 & $\mathrm{~F}$ & Trauma & $15 \times 12(180)$ & $11.5 \times 4(46)$ & $15 \times 11.5(172.5)$ & C & D \\
\hline 11 & 36 & $M$ & Trauma & $14 \times 12.5(175)$ & $11 \times 5(55)$ & $14 \times 12(168)$ & A & D \\
\hline 12 & 38 & $\mathrm{~F}$ & Trauma & $13.5 \times 10(135)$ & $10.5 \times 4.5(47.25)$ & $14 \times 10(140)$ & A & A \\
\hline 13 & 45 & M & Trauma & $12.5 \times 11(137.5)$ & $11.5 \times 4(46)$ & $12.5 \times 11(137.5)$ & B & D \\
\hline 14 & 32 & M & Pott's spine & $12 \times 10(120)$ & $10 \times 3(30)$ & $12.5 \times 11(137.5)$ & A & D \\
\hline 15 & 51 & $\mathrm{~F}$ & Trauma & $14 \times 11.5(161)$ & $12 \times 4.5(54)$ & $13.5 \times 11(148.5)$ & A & D \\
\hline 16 & 28 & M & $\begin{array}{l}\text { Transverse } \\
\text { myelitis }\end{array}$ & $13 \times 10.5(136.5)$ & $11.5 \times 4(46)$ & $13 \times 10(130)$ & A & A \\
\hline 17 & 31 & M & Trauma & $12 \times 10(120)$ & $10 \times 3.5$ & $11.5 \times 10(115)$ & A & B \\
\hline 18 & 53 & M & Trauma & $13.5 \times 11(148.5)$ & $10.5 \times 3.5(36.75)$ & $14 \times 11(154)$ & A & D \\
\hline 19 & 35 & $\mathrm{~F}$ & Trauma & $12.5 \times 10(125)$ & $11 \times 4(44)$ & $13.5 \times 10(135)$ & A & D \\
\hline 20 & 32 & M & Trauma & $15 \times 12(180)$ & $11.5 \times 5(57.5)$ & $15 \times 11(165)$ & A & D \\
\hline 21 & 41 & $M$ & Trauma & $14 \times 11.5(161)$ & $10.5 \times 4(42)$ & $14 \times 11(154)$ & A & D \\
\hline
\end{tabular}

Abbreviations: F, female; GBS, Guillian-Barre syndrome; IGVA, inferior gluteal vessel axis; M, male. 
had grade $\mathrm{C}$. Whereas on the assessment of the control group using institutional scoring system, only three patients had grade A (14.29\%). On the assessment of the control group, grade B $(n=2 ; 9.52 \%)$, grade C $(n=4 ; 19.04 \%)$, and grade D $(n=12 ; 57.14 \%)$ were observed.

\section{Discussion}

The ischial tuberosity is the most common site for pressure sores in people suffering from paraplegia, accounting for $28 \%$ of all ulcers. ${ }^{23,24}$ IPSs are the most common type of recurring pressure ulcers. ${ }^{19,23,24}$ Surgery is the established best modality for the treatment of most of the pressure ulcers occurring in the chronic myelopathic patients. ${ }^{25,26}$

IPSs are difficult to treat due to high recurrence and complication rates up to 40 to $50 \%$, despite successful surgery. ${ }^{13,24}$ Surgical reconstruction of IPSs must provide good-quality filling tissue, preventing the recurrence. 25,26 With conventional flaps there exists an unplugged residual subfascial void, which causes collection, infection, and recurrences, ${ }^{19-21,23}$ whereas in this pedicled chimeric flap on the IGVA, there is an adequate volume of well-vascularized muscle component on an independent perforator. The later by its increased mobility and potential of three-dimensional positioning, congruently fills the subfascial void and absorbs all the exudate, culls infection, and promotes healing. The first supporting evidence for this was less drainage, leading to early removal of the drain when compared with the conventional flap in the same patients (average drain removal time in chimeric IGVA flap side was 3.5 days vs. 9.5 days for the conventional flap and the difference was statistically significant). Similarly, the infection and recurrence complications were also less on the pedicled chimeric flap side. Only two closely relatable studies are by Legemate et $\mathrm{al}^{19}$ and $\mathrm{Ku}$ et $\mathrm{al}^{23}$ In the study by Ku et al, they used a perforator-based fasciocutaneous flap and another pedicled paddle of split gluteus maximus to fill the void. Their reported complication rate of seroma, hematoma, and recurrences was $20 \%$, probably due to limited mobility of split gluteal maximus paddle. Catherine et al in their study used the internal pudendal artery perforator flap with de-epithelized distal skin, which was folded for occluding the subfascial void. They reported complicated wound healing in $18 \%$ of cases. Again, all these could be attributed to the inadequately filled void. A well-vascularized gluteus maximus paddle also withstands a pressure of 80 to $100 \mathrm{~mm} \mathrm{Hg}^{23}$ over the ischium in the sitting posture. Though Daniel et $\mathrm{al}^{27}$ had shown that muscle tissues were highly susceptible to the pressure injury, Nola et $\mathrm{a}^{28}$ had noted in their study that the skin over the muscle covering the bone offered more resistance to pressure injury when compared with the skin alone covering the bone. Thus muscle paddle on an independent perforator has three distinct advantages: (1) highly vascularized tissue (supranormal homogenized blood supply) culls the infection in these clean-contaminated wounds by bringing in the whole immunity system and systemically administered antibiotics in proximity to the wall of the subfascial void,
Table 3 Overall institutional score for the assessment of outcome in the reconstruction of ischial pressure sores

\begin{tabular}{|c|c|c|}
\hline $\begin{array}{l}\text { Objective } \\
\text { factors } \\
\text { assessed }\end{array}$ & Status & Score \\
\hline \multirow[t]{4}{*}{ Flap status } & Flap necrosis & 0 \\
\hline & Congestion warranting re-surgery & 1 \\
\hline & Congestion managed conservatively & 2 \\
\hline & Healthy & 3 \\
\hline \multirow[t]{4}{*}{ Dehiscence } & $\begin{array}{l}\text { Infection, dehiscence envisaging debride- } \\
\text { ment, and further flap primary movement }\end{array}$ & 0 \\
\hline & $\begin{array}{l}\text { Infection, dehiscence envisaging debride- } \\
\text { ment, and secondary suturing }\end{array}$ & 1 \\
\hline & $\begin{array}{l}\text { Infection-collection let out, dehiscence } \\
\text { healed with secondary intention }\end{array}$ & 2 \\
\hline & $\begin{array}{l}\text { No infection, no dehiscence, primary } \\
\text { healing obtained }\end{array}$ & 3 \\
\hline \multirow[t]{4}{*}{ Recurrence } & $\begin{array}{l}\text { Recurrence envisaging another locore- } \\
\text { gional flap }\end{array}$ & 0 \\
\hline & $\begin{array}{l}\text { Recurrence envisaging primary movement } \\
\text { of the flap }\end{array}$ & 1 \\
\hline & $\begin{array}{l}\text { Recurrence uneventfully healed with } \\
\text { offloading }\end{array}$ & 2 \\
\hline & No recurrence & 3 \\
\hline \multirow{3}{*}{$\begin{array}{l}\text { Contour of } \\
\text { the recon- } \\
\text { structed } \\
\text { site after } 6 \\
\text { months }\end{array}$} & Depressed and thinning & 0 \\
\hline & Flat & 1 \\
\hline & Contour maintained & 2 \\
\hline
\end{tabular}

Notes: Outcomes (maximum score-11; minimum score-0).

Score 9-11 (grade A)-excellent.

Score 7-8 (grade B)-good.

Score 5-6 (grade C)-fair.

Less than 5 (grade D)-poor.

(2) it obliterates all the dead spaces, and (3) it provides relative bulk over the bony prominence. ${ }^{29-33} \mathrm{~A}$ muscle flap on an independent perforator serves all these purposes fully, better than any muscle containing conventional flaps..$^{9,29-33}$ Also, the paddles on the independent perforator with their free excursion allow tension-free reconstruction. All these factors facilitated better outcomes in our study. Because of the high recurrence rates of IPSs, surgeons should consider the possibility of future secondary flap surgery in any flap selection. Therefore, when choosing a flap, the surgeon must exercise the utmost care not to violate the potential prospect of surrounding locoregional flaps by not venturing into the surrounding skin, muscles, and vascular plexus. Though our chimeric pedicled IGVA flap does not affect the prospect of surrounding locoregional flaps, redoing/re-advancing the same flap is not possible.

The limitation of the study is the small sample size, but the strength of the study is the clinical establishment of the benefit of chimeric pedicled IGVA flap in minimizing the residual void related complications. Besides, we had also established the feasibility in a preliminary cadaver study. 


\section{Conclusion}

This anatomically construed flap, a new addendum in the armamentarium of reconstruction of IPSs, with its potential to congruently fill the ischiogluteal subfascial void may provide a lasting solution for preventing the recurrence. This requires large-scale study to establish the advantage of the proposed chimeric pedicled flap on IGVA.

\section{Financial Support and Sponsorship \\ None.}

\section{Conflict of Interest}

None declared.

\section{References}

1 National Pressure Ulcer Advisory Panel, European Pressure Ulcer Advisory Panel and Pan Pacific Pressure Injury Alliance, In: Haesler E, ed. Prevention and Treatment of Pressure Ulcers: Quick Reference Guide. Osborne Park, Australia: Cambridge Media; 2014

2 Dansereau JG, Conway H. Closure of decubiti in paraplegic. Report of 2000 Cases. Plast Reconstr Surg 1964;33:474-480

3 Kwon R, Janis JE, Pressure sores. In: Neligan PC, ed. Plastic Surgery. 4th ed. Philadelphia, PA: Saunders Elsevier; 2018 351-382

4 Chen Y, Devivo MJ, Jackson AB. Pressure ulcer prevalence in people with spinal cord injury: age-period-duration effects. Arch Phys Med Rehabil 2005;86(6):1208-1213

5 Cushing CA, Phillips LG. Evidence-based medicine: pressure sores. Plast Reconstr Surg 2013;132(6):1720-1732

6 Lefèvre $C$, Bellier-Waast F, Lejeune $F$, et al. Ten years of myocutaneous flaps for pressure ulcers in patients with spinal lesions: analysis of complications in the framework of a specialised medical-surgical pathway. J Plast Reconstr Aesthet Surg 2018;71(11):1652-1663

7 Berlemont M, Keromest R. Dangers of ischiectomy in ulcers in the paraplegic patient. Review of 236 records [in French]. Rev Chir Orthop Repar Appar Mot 1987;73(8):656-664

8 Culkin DJ, Wheeler JS Jr, Chintam R, Lopez E, Nemchausky BA. Perineal urethrocutaneous fistula complicating ischiectomy. J Urol 1988;139(4):811-812

9 Burm JS, Hwang J, Lee YK. A new option for the reconstruction of primary or recurrent ischial pressure sores: hamstring-adductor magnus muscle advancement flap and direct closure. Ann Plast Surg 2018;80(4):400-405

10 Kumar U, Jain P. Infragluteal fasciocutaneous flap for management of recurrent ischial pressure sore. Indian J Plast Surg 2018;51(1):70-76

11 Scheufler O, Farhadi J, Kovach SJ, et al. Anatomical basis and clinical application of the infragluteal perforator flap. Plast Reconstr Surg 2006;118(6):1389-1400

12 Scheflan M, Nahai F, Bostwick J III; ScheflanM. Gluteus maximus island musculocutaneous flap for closure of sacral and ischial ulcers. Plast Reconstr Surg 1981;68(4):533-538

13 Higgins JP, Orlando GS, Blondeel PN. Ischial pressure sore reconstruction using an inferior gluteal artery perforator (IGAP) flap. Br J Plast Surg 2002;55(1):83-85

14 Lee SS, Huang SH, Chen MC, Chang KP, Lai CS, Lin SD. Management of recurrent ischial pressure sore with gracilis muscle flap and $\mathrm{V}$-Y profunda femoris artery perforator-based flap. J Plast Reconstr Aesthet Surg 2009;62(10):1339-1346
15 Grassetti L, Scalise A, Lazzeri D, et al. Perforator flaps in late-stage pressure sore treatment: outcome analysis of 11-year-long experience with 143 patients. Ann Plast Surg 2014;73(6):679-685

16 Cope C, Barry P, Hassall M, Barnett R, Richards M, Vandervord J. $\mathrm{V}-\mathrm{Y}$ advancement hamstring myocutaneous island flap repair of ischial pressure ulcers. Aust N Z J Surg 1995;65(6):412-416

17 Lemaire V, Boulanger K, Heymans O. Free flaps for pressure sore coverage. Ann Plast Surg 2008;60(6):631-634

18 Korambayil PM, Allalasundaram K, Balakrishnan T. Perforator propeller flaps for sacral and ischial soft tissue reconstruction. Indian J Plast Surg 2010;43(2):151-157

19 Legemate CM, van der Kwaak M, Gobets D, Huikeshoven M, van Zuijlen PP. The pedicled internal pudendal artery perforator (PIPAP) flap for ischial pressure sore reconstruction: technique and long-term outcome of a cohort study. J Plast Reconstr Aesthet Surg 2018;71(6):889-894

20 Friedrich JB, Pederson WC, Bishop AT, Galaviz P, Chang J. New workhorse flaps in hand reconstruction. Hand (N Y) 2012;7(1):45-54

21 Balakrishnan TM, Alalasundaram KV. Reconstruction in the revascularized diabetic foot. J Diab Foot Complications 2012;4(2):46-56

22 Balakrishnan TM, Mariappan BK, Jaganmohan J. Retrospective cohort observational study on the single best perforator-based Pacman flap in the reconstruction of stage iv sacral region pressure ulcers. Indian J Plast Surg 2020;53(2):266-272

23 Ku I, Lee GK, Yoon S, Jeong E. A dual padding method for ischial pressure sore reconstruction with an inferior gluteal artery perforator fasciocutaneous flap and a split inferior gluteus maximus muscle flap. Arch Plast Surg 2019;46(5):455-461

24 Sameem M, Au M, Wood T, Farrokhyar F, Mahoney J. A systematic review of complication and recurrence rates of musculocutaneous, fasciocutaneous, and perforator-based flaps for treatment of pressure sores. Plast Reconstr Surg 2012;130(1):67e-77e

25 Singh R, Singh R, Rohilla RK, Siwach R, Verma V, Kaur K. Surgery for pressure ulcers improves general health and quality of life in patients with spinal cord injury. J Spinal Cord Med 2010;33(4):396-400

26 Lala D, Dumont FS, Leblond J, Houghton PE, Noreau L. Impact of pressure ulcers on individuals living with a spinal cord injury. Arch Phys Med Rehabil 2014;95(12):2312-2319

27 Daniel RK, Priest DL, Wheatley DC. Etiologic factors in pressure sores: an experimental model. Arch Phys Med Rehabil 1981;62(10):492-498

28 Nola GT, Vistnes LM. Differential response of skin and muscle in the experimental production of pressure sores. Plast Reconstr Surg 1980;66(5):728-733

29 Kuo PJ, Chew KY, Kuo YR, Lin PY. Comparison of outcomes of pressure sore reconstructions among perforator flaps, perforator-based rotation fasciocutaneous flaps, and musculocutaneous flaps. Microsurgery 2014;34(7):547-553

30 Vasconez LO, Bostwick J III, McCraw J. Coverage of exposed bone by muscle transposition and skin grafting. Plast Reconstr Surg 1974;53(5):526-530

31 Minami RT, Mills R, Pardoe R. Gluteus maximus myocutaneous flaps for repair of pressure sores. Plast Reconstr Surg 1977;60(2):242-249

32 Ger R, Levine SA. The management of decubitus ulcers by muscle transposition. An 8-year review. Plast Reconstr Surg 1976;58(4):419-428

33 Foster RD, Anthony JP, Mathes SJ, Hoffman WY. Ischial pressure sore coverage: a rationale for flap selection. $\mathrm{Br}$ J Plast Surg 1997;50(5):374-379 